\title{
What makes flunisolide different among inhaled corticosteroids used for nebulization: a close look at the role of aqueous solubility
}

\author{
Ahmad Kantar \\ Pediatric Asthma and Cough Center, Istituti Ospedalieri Bergamaschi, Bergamo, Italy
}

\begin{abstract}
Evidence-based management of bronchial asthma and wheezing in children and adults recommends the employment of inhaled corticosteroids (ICSs). Difficulty in using some inhalation devices for ICS delivery, such as pressurized metered-dose and dry-powder inhalers, is common among young children and in the elderly, and for that reason, they are replaced with nebulizers. We reviewed comparative studies that evaluated funisolide with other ICSs currently available on the market, including beclomethasone dipropionate, fluticasone propionate, and budesonide. Moreover, we assessed the physicochemical properties of these ICSs in determining drug fate in the lung. Data indicate that the flunisolide output in respirable particles by any type of pneumatic nebulizer (traditional, open breath or breathenhanced) is superior to the output of other ICSs. This is principally attributed to the higher water solubility of flunisolide. Furthermore, in vivo simulation studies demonstrate that the intersubject variability of the inhaled dose among asthmatic children was much greater for suspensions of fluticasone propionate and beclomethasone dipropionate than for those of flunisolide. The physicochemical properties and pharmacokinetic profile of flunisolide favor its employment in nebulization.
\end{abstract}

Key words: Inhaled corticosteroids; flunisolide; nebulization; drug output; particle size.

Correspondence: Ahmad Kantar, Pediatric Asthma and Cough Center, Istituti Ospedalieri Bergamaschi, Gruppo Ospedalieri San Donato, Via Forlanini 15, 24036 Ponte San Pietro (BG), Italy. E-mail: kantar@centropediatricotosse.com

Contributions: AK is the only author that contributed to the preparation of this manuscript.

Conflict of interest: AK received lecture fees from Valeas, Menarini, Chiesi, Italchimici, Merck Sharp \& Dohme, Sanofi and Novartis (Italy). AK is a member of the Editorial Board of Multidisciplinary Respiratory Medicine.

Funding: This research did not receive any specific grant from funding agencies in the public, commercial, or not-for-profit sectors. Availability of data and materials: Qualified researchers may request access to study documents and data reported in this manuscript. Ethics approval and consent to participate: Not applicable. 


\section{Introduction}

Inhaled corticosteroids (ICSs) are anti-inflammatory drugs that are largely indicated in the first-line management of subjects with various respiratory diseases. Among ICSs, four are currently accessible on the market for nebulization: budesonide (BUD), fluticasone propionate (FP), flunisolide (FLU), and beclomethasone dipropionate (BDP). These ICSs possess different chemical structures and distinct physicochemical properties that form the basis of their different pharmacokinetic (PK) and pharmacodynamic (PD) properties. To better comprehend the safety and efficacy of these ICSs, it is important to examine the fate of drug molecules in the body during nebulization and inhalation. ICSs exhibit therapeutic effects after deposition and distribution in pulmonary tissues at the site of action. Depending on the size of the particles, the delivery device used as well as the patient respiratory pattern, distinct fractions of the ICS are deposited in the upper respiratory tract (oropharynx), central airways (bronchi and bronchiole), or deep pulmonary tissues (alveoli) [1,2]. Deposition of the ICS in the lungs allows the targeted delivery and induction of the desired therapeutic effects. Guidelines for the treatment of respiratory diseases as well as for aerosol therapy do not provide detailed guidance on the choice of the most appropriate device in a particular clinical setting [3]. Therefore, according to local practices and accessibility, there is great inconsistency among countries in the employment of different devices for administering aerosol therapy $[4,5]$. An outstanding tendency in pediatric aerosol therapy is the liberal decline in the choice of nebulizers in favor of pressurized metered dose inhalers (pMDIs) and dry-powder inhalers (DPIs); nevertheless, over 70 countries worldwide still use nebulization to deliver ICSs for both children and adults for asthma and chronic obstructive pulmonary disease [6]. In this article, we review our existing knowledge of ICSs for nebulization with a focus on FLU by responding to frequently asked questions regarding why this drug is the most appropriate for nebulization.

\section{Are all ICSs born equally?}

ICSs are synthetic corticosteroid analogs created from basic steroid molecules. In 1972, BDP became the first corticosteroid to be developed as a therapeutic aerosol [7]. Formulations of ICS products share numerous properties to enhance local potency and minimize systemic exposure. Specific ICS molecules have distinctive properties that affect their formulation and use. In terms of pharmacology, they differ in physicochemical properties that dictate their PK and PD characteristics. In the clinical setting, balancing favorable and unfavorable properties presents challenges in determining whether a molecule offers significant advantages in either efficacy or safety.

In general, the PK and PD properties of an ICS dictate its efficacy and safety; nevertheless, because there are several characteristics of individual agents that influence these properties, the global effect is sometimes uncertain and often controversial [1]. The optimal ICS would be an agent that displays significant local and sustained effects in the airways with negligible systemic effects owing to limited bioavailability and prompt systemic clearance [8].

The preferred drug would exert selective topical effects with minimal systemic absorption or rapid inactivation after absorption [9]. Several PK and PD features of ICSs have been identified as having a role in their overall efficacy and safety profile. Due to the numerous properties that concomitantly influence ICS action and safety, it is difficult to determine the precise effect of any distinct property. For example, the receptor binding affinity of available
ICS agents varies 10-100-fold, and oral bioavailability varies 20fold. Although the protein binding of available agents is relatively consistent, ranging from $71 \%$ to $99 \%$, lipophilicity varies over 100 -fold, and half-lives generally vary between 5 to $14 \mathrm{~h}$. Perhaps because of the similarities or the numerous differences among molecules, no single agent seems to have significant advantages or confers additional risks over any other in clinical practice. Moreover, the behavior of the therapeutic formulation during delivery can vary between devices.

The exponential relationship between in vitro glucocorticoid receptor binding affinity and therapeutic dose for ICS is evidence that more potent molecules can be administered at much lower doses to achieve similar clinical efficacy. Furthermore, the structural features of ICS that give rise to more potent molecules also drive lower systemic exposure, and together these factors can improve the therapeutic index. Relative glucocorticoid receptor binding affinity relative to dexamethasone (affinity of 100) is 2989 for fluticasone furoate (FF) DPI, 2100 for mometasone furoate DPI, 1775 for FP DPI, 53 for BDP pMDI, 1345 for beclomethasone 17-monopropionate, 935 for BUD, 190 for FLU pMDI and 12 for oral prednisolone [7].

Enhanced inhaled ICS potency leads to greater lipophilicity, slower dissolution and pulmonary absorption of inhaled drug particles with longer retention times in the airways. This also results in a longer duration of action and permits less frequent dosing. Once absorbed, more potent inhaled corticosteroids have higher plasma protein binding, lower unbound fractions in the plasma and larger volumes of distribution. These molecules are also good substrates for drug-metabolizing enzymes and have high systemic clearance, high first-pass metabolism and low oral bioavailability of the swallowed dose [7].

A prolonged pulmonary residence time is apparent when the elimination half-life following inhaled administration is significantly longer than found following intravenous administration. This tendency has been noted for the more lipophilic inhaled corticosteroids. The main consequence of this appears to be a longer duration of action rather than greater efficacy per se, with the corticosteroid with the longest lung retention time (such as FF) being suitable for once daily dosing, and those with shorter lung retention times (such as FP) requiring twice daily dosing regimens [7].

An advantage of ICSs is their high potency, which allows occupancy of a glucocorticoid receptor at a lower dose than that of less potent agents. The potency of topical corticosteroids varies among different agents, and characterizing the relative potency of available therapies is challenging and imperfect. For example, FP is marketed in all pMDI, DPI and nebulization formulas and has a high therapeutic index and efficacy $[10,11]$. For several years, FP has been employed successfully for all severities of asthma and has proven to be well tolerated. No clinically important systemic effects are reported for its normal therapeutic dose range [10-13]. By contrast, pharmacokinetic studies have suggested hypothalamic-pituitary-adrenal suppression with higher doses. However, those high-dose studies involve normal volunteers [14-19] or subjects with mild asthma who were receiving inappropriately high doses, well in excess of those normally recommended to obtain disease control $[20,21]$. In patients with moderate or severe asthma requiring higher doses of ICSs, factors such as airflow obstruction and ventilation-perfusion mismatch could alter drug deposition in the lung and alter systemic absorption. Brutshe et al. [22] demonstrated through a double-blind, randomized, crossover study that the systemic availability of FP is substantially less in patients with moderate to severe asthma than in healthy controls. There is little information on factors that influence the systemic bioavailability of ICSs, especially for drugs with minimum oral bioavailability, such as FP, in which drug delivery and pulmonary deposition have 
key roles. Almost all FP present in the systemic circulation is absorbed in an unchanged active form via the lungs $[23,24]$. Once present in the bloodstream, this drug remains potent, with a high binding affinity to the extrapulmonary corticosteroid receptor. Until now, despite the characteristic differences that arise in the airways in asthma, it had been assumed that drug deposition, pulmonary drug absorption, and systemic effects measured in healthy individuals could predict outcomes in people with asthma. Asthma is, however, characterized by reversible and nonhomogeneous airflow obstruction, leading to ventilation-perfusion mismatch. Several studies, some by using three-dimensional imaging techniques [25], have shown that the uniformity of deposition in the lungs is greater in healthy individuals than in patients with airway disease. It is suggested that the narrowing of airways in asthma results in reduced penetration of the drug particles and subsequently increased deposition in the central rather than in peripheral airways. In asthma, inflammation definitely involves large airways, but histopathological evidence has clearly shown that the inflammation involves small airways as well. Drug particles that are deposited in the conducting airways are more subject to mucociliary clearance than those deposited in the alveoli, which are completely absorbed. Consequently, for a drug with a relatively slow dissolution rate in the lung, such as FP [24], drug deposited in the airways is more likely to be removed from the lung by mucociliary clearance and then swallowed, leading to a lower degree of systemic exposure than that seen in healthy subjects.

\section{How is a nebulizer chosen?}

There has been substantial progress in drug delivery technology over the last decades. New devices that are outstandingly improved in delivering respirable drugs to the airways have been promoted. Since the introduction of pMDIs, there has been a trend of progressive decrease in the use of traditional nebulizers in favor of smart and more portable devices. Nevertheless, in various countries, traditional nebulizers continue to be commonly employed, somewhat for historical and economic motives.

Nebulizers allow drug delivery to very young children and elderly adults through passive inhalation and are less reliant on patient synchronization, cooperation and acceptance. Delivery of ICSs by nebulization represents a valid and alternative method of aerosol therapy for infants and elderly adults, who are unable or refuse to use pMDIs with spacers or DPIs.

In a review article, Melani indicated that nebulizers may be considered as an effective alternative to inhalers for delivering ICSs and can be recommended to asthmatic and COPD subjects who are unwilling or unable to use inhalers [6]. Results of the review showed that nebulized BDP, FP and FLU are effective alternatives to nebulized BUD in asthma and COPD. From a pharmaceutical perspective, a primary advantage of nebulizers is the use of water-based formulations, which are relatively simple to prepare for aqueous soluble drugs making them less expensive compared with the processing required for pMDI and DPI aerosol formulations.

The cheapest and most commonly used devices are pneumatic nebulizers characterized from old atomizers by their means of preventing delivery and recycling of large particles [26]. Baffles or impaction sites are assembled to block the primary spray emerging from the atomizer jet. Cycling of the fluid and baffling control the velocity, size and volume flow of the delivered drug, permitting the release of a cloud of respirable particles [27].

New technical innovations for nebulizers have drastically reduced drug wastage and increased output. Innovative categories of nebulizers have been promoted, among which are the open vent, breath-enhanced open vent, breath-activated devices and mesh nebulizers $[28,29]$. Although ultrasonic nebulizers are more efficient and compact than jet nebulizers, they are entirely inadequate to deliver ICS suspensions.

Vibrating mesh technology is an alternative innovation to jet nebulizers. Numerous recent electronic nebulizers that employ a vibrating mesh or plate with multiple holes to generate monodispersing, fine-particle, low-velocity aerosol clouds are being released in the market and are increasingly used to deliver specific drugs. These devices are highly efficient in delivering aerosols to the peripheral airways, such that the nominal dose of drugs to be aerosolized could be substantially reduced. Moreover, the residual volume of the formulation left in these devices after nebulization is negligible, leading to prominent improvements in the cost-effectiveness of administering costly medications. Since these devices nebulize at a faster rate than conventional jet or ultrasonic nebulizers, the duration of each treatment is reduced. These devices efficiently nebulize solutions and suspensions and have overcome many of the limitations associated with forerunning nebulizers, and they offer the adaptability to adjust the aerosol characteristics according to the clinical need for which they are employed [30].

Jet and ultrasonic nebulizers entered the market several decades before mesh devices. Therefore, the mesh nebulizer has had to compete for a share of the pre-existing market since the launch of the first mesh nebulizer in 1993. In an ever-growing nebulizer market, perhaps as a consequence of lower prices and the increase in respiratory diseases worldwide, the jet nebulizer continues to dominate the market in several countries. Moreover, many pharmaceuticals have been developed and packaged for jet nebulizer use; thus, mesh nebulizers are not designed as an immediate substitution for jet nebulizers.

Drug formulations can have a key impact on the aerosol output rate and the output of drug in respirable particles. Suspensions with a high surface tension, such as BUD, can decrease the performance of vibrating mesh nebulizers regarding the output rate and the inhaled mass. Moreover, obstruction of mesh holes during nebulization has been reported with drug suspensions [30].

The usage of mesh nebulizers to deliver ICS is scarce due to the limited number of studies in this field and the lack of clinical experience. In addition, their higher cost remains a limiting factor in their expansion in the market. Moreover, even if the best nebulizer is selected based on cost, ease of use, and clinical efficacy, a critical factor is the patient's ability to use the device.

A wide range of micro- and nanoemulsion-based formulations have been proposed for oral, topical and parenteral administration, which, by mimicking the physicochemical properties of solutions, "solubilize" poorly water-soluble drugs in an aqueous formulation, indicating potential for use in drug delivery systems $[31,32]$. Nanoemulsions, because of their high solubilizing and drug protection features have the potential to deliver active drug compounds to the lungs. With the advantage of solution-like physicochemical properties of nanoemulsions, it is hypothesized that nanoemulsions perform as a solution when nebulized and will demonstrate improved aerosolization performance over suspension formulations. Amani et al. evaluated in vitro performance of a nebulized nanoemulsion-based formulation containing budesonide with respect to budesonide suspension formulation delivered from a jet and mesh nebulizers. A smaller MMAD with improved aerosol output was observed in the nanoemulsion preparations [31].

Mixing nebulizable medications for simultaneous inhalation is an obvious way to reduce the duration of nebulization and is a commonly used procedure. The problem of compatibility of inhalation admixtures received little attention and has been sporadically researched. Even if the admixtures are physically and chemically compatible in the nebulizer, the aerodynamic behavior and 
out-put may be influenced by mixing [33]. Melani [34] evaluated the effect of mixinig BUD or BDP with albuterol and ipratropium bromide from an open-vent and breath-enhanced nebulizer. Results demonstrated that mixing did not substantially reduced the respirable mass of the examined drugs. In our previously study, using a conventional and an open-vent nebulizer, we have demonstrated that mixing FLU or BDP with salbutamol did not decrease drug out or modified particle size [35]. Droplet and particle size distribution in the delivered aerosol and incompatibilities arising during nebulization of the admixtures should be addressed for each mixture before prescription.

Prescribing the most appropriate nebulized therapy should take into consideration the available drug formulations, combinations, and devices, as well as the patients' pulmonary function, skills, and preferences [36].

There are many challenges with the use of inhalers and nebulizers, and no one device suits all patients [37]. Each nebulizer has different technical properties that dictate its performance. Knowledge of nebulization procedures and of the behavior of a drug during nebulization is essential for drug-device matching. Patient factors to consider in device selection include disease status, physical and mental capabilities, past experiences with inhalers, preferences and satisfaction with their inhalers [37]. However, several drawbacks have been reported with using nebulizers including considerable heterodispersity in concertation of delivered drug, device preparation, possible contamination, lengthy treatment time, drug waste or high cost. In a nation-wide survey Melani et al. demonstrated that the use of nebulizers in Italy is widespread, with either occasional or regular use for upper or lower airways diseases. However, the use and maintenance of home nebulizers were heterogenous and not optimal [38].

\section{Why is flunisolide appropriate for nebulization?}

The physicochemical features of the preparation and its comportment during the process of nebulization are essential aspects to be considered when prescribing inhalation therapy. Not all drugs are appropriate for the nebulization process. Water solubility and formulation viscosity govern the quantity of drug delivered in particles able to reach the therapeutic target. If a drug solution in a nebulizer chamber is homogeneously distributed, each aerosol droplet is likely to have a relatively uniform drug concentration during nebulization. Nevertheless, water in the drug formulation evaporates during nebulization, and consequently, the drug concentration in the delivered cloud will increase $[39,40]$. Corticosteroids available for nebulization, depending on their water solubility, may either be in solution, such as FLU, or in suspension, such as FP, BUD and BDP. Högger and Rohdewald rated the water solubility of ICSs at $37^{\circ} \mathrm{C}$ as $140 \mu \mathrm{g} / \mathrm{ml}$ for FLU, $16 \mu \mathrm{g} / \mathrm{ml}$ for BUD, $0.14 \mu \mathrm{g} / \mathrm{mL}$ for FP and $0.13 \mu \mathrm{g} / \mathrm{mL}$ for BDP [41]. Most solution formulations are a mixture of the active drug and a diluent forming a continuous phase. On the other hand, suspensions form two phases become challenging to nebulize. The high solubility of FLU yields a drug advantage in nebulization. Studies comparing the output of different ICSs from the same nebulizer are still lacking. In our previous studies, the output from two nebulizers (traditional and open vent) for FLU, BDP, and BUD delivery was investigated using a multistage liquid impinger method [42-44]. The data showed that FLU output was superior to that of the other two drugs. Moreover, the mass median aerodynamic diameter (MMAD) of nebulized FLU was smaller than that of BDP and BUD. The drug output in respirable particles $<4.3 \mu \mathrm{m}$ as a percentage of the nominal doses of FLU, BUD and BDP were $25.7 \%, 14.7 \%$, and $11.5 \%$, respectively, from the traditional nebulizer and $24.7 \%, 11.6 \%$, and $7.2 \%$, respectively, from the open-vent nebulizer (Figure 1).

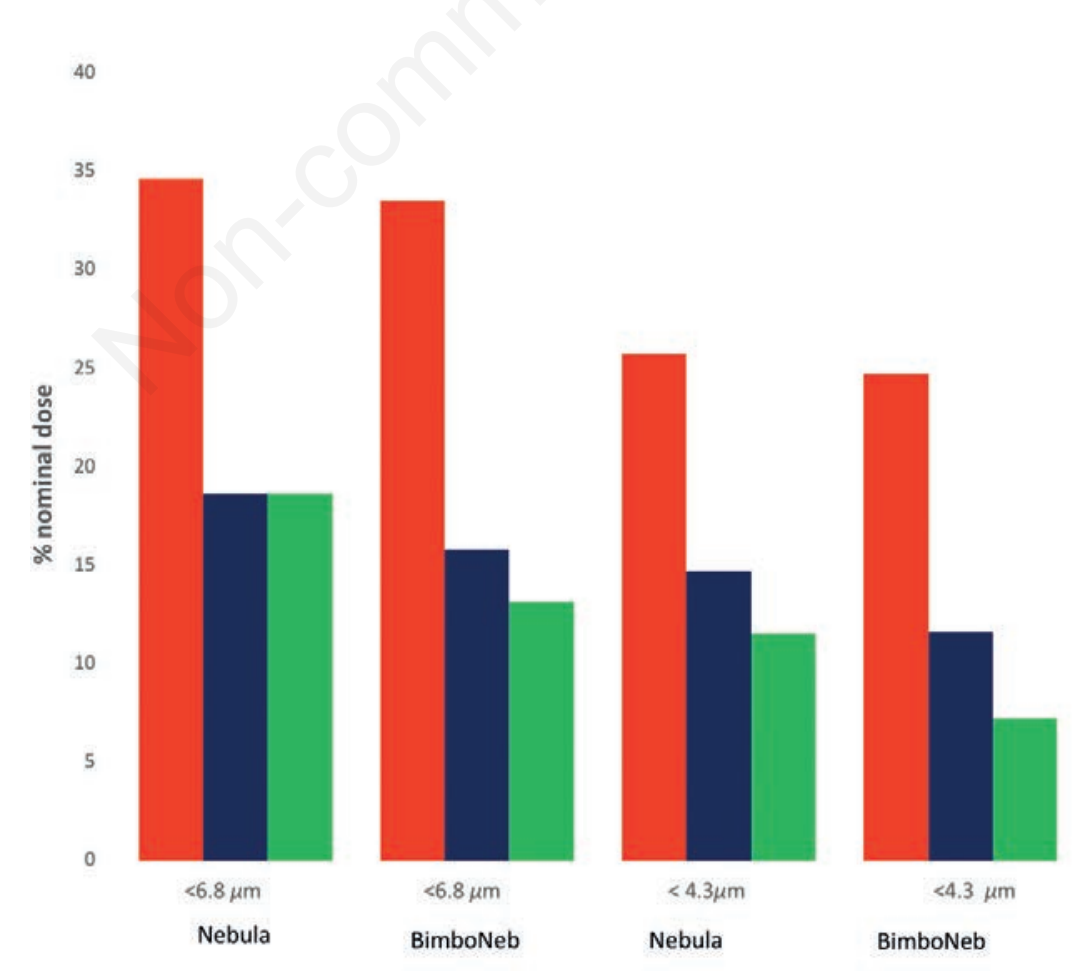

Figure 1. Output in particles $<6.8 \mu \mathrm{m}$ and $<4.3 \mu \mathrm{m}$ as percentages of the nominal dose of nebulized flunisolide (nominal dose $600 \mu \mathrm{g}$ ); red bars, budesonide (nominal dose $500 \mu \mathrm{g}$ ); blue bars; beclomethasone DP (nominal dose $800 \mu \mathrm{g}$ ); green bars, from two different nebulizers. The jet nebulizers used were Nebula (a conventional pneumatic device, Markos-Mefar, Bovezzo, Italy) and BimboNeb (an openvent nebulizer, Markos-Mefar) (data from references 47-49). 
In another study, we investigated the inhaled doses of three ICSs delivered via nebulization for asthmatic children [45]. The interaction of a child with a device has an overwhelming effect on the inhaled dose. The aim of that study was to investigate whether children with asthma inhale the same ratios of the prescribed dose delivered by the same nebulizer for FP, BDP and FLU. A 'breathenhanced, open vent' nebulizer (Pari TurboBOY, Germany) was used, and the following drug formulations were employed: FP suspension $(500 \mu \mathrm{g} / 2 \mathrm{ml}$ nebule) BDP suspension $(0.8 \mathrm{mg} / 2 \mathrm{ml}$ nebule) and FLU solution ( $30 \mathrm{mg} / 30 \mathrm{ml}$ solution). The children inhaled each of the drug preparations for $5 \mathrm{~min}$. The results revealed that the prescribed dose bears little resemblance to the proportion of drug the children actually inhale and that this is largely dependent on the formulation of the drug. Following nebulization, the children in the study would have inhaled $13 \%$ of the prescribed dose of FP, $21 \%$ of BDP and $25 \%$ of FLU. However, the percentage of the dose inhaled by drug particles that were less than $5 \mu \mathrm{m}$ and therefore more likely to reach the lungs were only $5 \%$ and $8 \%$ of the prescribed doses of FP and BDP, respectively. Hitherto, the amount of FLU inhaled in particles less than $5 \mu \mathrm{m}$ was significantly greater at $16 \%$. These variances were augmented further when the amount of drug contained in particles less than $3 \mu \mathrm{m}$ was compared. Surprisingly, the variation in the quantity of drug inhaled was larger among children who inhaled the suspensions of BDP and FP than those of FLU. This fact has not been previously reported and suggests that drug dispersion in the nebulizer mixture, drug behavior during nebulization or the child's breathing pattern through the nebulizer may have noteworthy effects on the amount of drug delivered from suspensions and that this is not predictable. It is of interest that a currently discontinued preparation of BDP resulted in very little drug exiting the nebulizer in particles small enough to reach the lower airways $[46,47]$. and that this was associated with a poor clinical effect $[48,49]$. Other factors, such as the choice of nebulizer, may have a profound effect on the dose of nebulized corticosteroids a patient may inhale. For example, in vitro studies have demonstrated that the dose of budesonide that a 10year-old is likely to inhale from breath-enhanced, open-vent nebulizers is almost four times greater than that from an open-vent nebulizer and twice greater than that from a conventional nebulizer [50].

\section{How is nebulized flunisolide handled in the lungs?}

The target of ICS treatment is to achieve an appropriate antiinflammatory outcome in the airways while outstandingly reducing adverse local and systemic effects.

Common means of retaining inhaled drugs in the lungs include tissue entrapment (e.g., water soluble di-bases) and the slow dissolution of particles of poorly soluble drugs such as corticosteroids
[51]. For compounds with high water solubility, sustained local tissue concentration and hence the therapeutic effect is influenced mainly by the extent of tissue binding or tissue entrapment, which is governed by molecular properties rather than material or formulation properties. For slowly dissolving compounds, the extent of the therapeutic effect is sensitive to the material properties governing the solubility and/or dissolution rate. This principle has been demonstrated experimentally: a difference in systemic exposure between two formulations with similar aerodynamic particle size distributions was found to be consistent with the predicted difference in the dissolution rate [52]. A relationship between dissolution rate and the rate of detection of drug in the plasma has also been reported [53]. Dissolution in vivo is influenced not only by the properties of the drug, such as solubility and specific surface area - which can be controlled and measured in an in vitro setting - but also by physiological factors, including the composition of airwaylining fluid, permeability of the airway epithelium, and rate of particle clearance, all of which vary between different regions of the lung. For example, epithelial permeability for many compounds (depending upon the molecular properties) is significantly greater in respiratory districts than in the conducting airways, and permeation could conceivably substitute dissolution as the rate limiting step as the deposition site moves from the peripheral to the central lung. The causality between the rate of dissolution and the clinical performance of an ICS is complex, but differences in the dissolution rate between ICSs with otherwise similar aerosol performance (with potential effects on local and systemic bioavailability and drug safety) have been demonstrated [54,55].

Sakagami et al. [56] evaluated the dissolution of various respirable ICSs in $\leq 5.8$ or $6.5 \mu \mathrm{m}$ particles in a simulated lung lining fluid. Dissolution in $10 \mathrm{ml}$ of the simulated lung lining fluid was determined over time in a Transwell dish. The results demonstrated that while ICSs with high-to-intermediate solubility [FLU, triamcinolone acetonide (TAA) and BUD] were capable of first order "sink" and complete dissolution in $6 \mathrm{~h}$, ICSs with poor solubility, including FP (FP, BDP, mometasone furoate, and ciclesonide), resulted in pseudozero-order "non-sink", slow and limited dissolution. The aerosol dissolution rate constant was well correlated with solubility. For FP, but not for highly soluble FLU, dissolution was kinetically aerosol mass dependent.

Wiedemann et al. evaluated the aqueous solubility and the relative affinity of some CSs (BUD, TAA, dexamethasone, and FLU) for lung surfactant using a native extract of bovine lung (Survanta) [57]. The aqueous solubility of the drugs at $37^{\circ} \mathrm{C}$ was $19.6,35.8$, 104 , and $120 \mu \mathrm{g} / \mathrm{mL}$, respectively. The quantity of drug dissolved in Survanta was amplified with solubilization of $0.019,0.023$, 0.014 , and $0.02 \mu \mathrm{g}$ of the drug per $\mu \mathrm{g}$ of Survanta. The amount of surfactant per $\mathrm{kg}$ of body weight was estimated to be between 8-24 $\mathrm{mg}$ [58]. The residence time of a drug in the lung is reliant on its solubilization in the surfactant (Table 1).

Table 1. Solubility and dissolution of ICSs in water and in bronchial fluid in vitro.

\begin{tabular}{lccc} 
ICS & $\begin{array}{c}\text { Water solubility, } \mu \mathrm{g} / \mathrm{ml} \\
\text { (ref 46) }\end{array}$ & $\begin{array}{c}\text { Solubilization in Survanta, } \\
\text { a native extract of bovine lung, } \mathbf{H g} / \mathrm{ml} \\
\text { (ref 68) }\end{array}$ & $\begin{array}{c}\text { Dissolution time } \\
\text { (human bronchial fluid in vitro) } \\
\text { (ref 46) }\end{array}$ \\
Beclomethasone dipropionate & 0.13 & - & - \\
Beclomethasone 17-propionate & 15.5 & 35.8 & - \\
\hline Triamcinolone acetonide & 21 & 19.6 & - \\
Budesonide & 16 & 120 & $6 \mathrm{hm}$ \\
\hline Flunisolide & 140 & - & $2 \mathrm{~min}$ \\
Fluticasone 17-propionate & 0,14 & & $8 \mathrm{~h}$
\end{tabular}


Pulmonary residence time is governed by the release rate of the inhaled particle, the degree of absorption of the dissolved drug across the pulmonary membranes and the mucociliary clearance [59]. The mean absorption times are 5-9 hours for FP and 0.3-1.8 hours for BUD [18]. The prolonged extracellular pulmonary residence of FP, as indicated by the rather prolonged mean absorption time, is a result of its extremely low solubility. The formation of intracellular ester depots is an alternative mean of protracting pulmonary residence. Long residence times in the extracellular environment have been estimated for FP and TAA, whereas BUD and FLU tend to fade quickly $[53,60]$. These properties are correlated to pulmonary solubility, which seems to be the rate-limiting step in pulmonary absorption $[60,61]$. Laboratory studies have demonstrated that a substantial portion of BUD undergoes intracellular esterification [61]. Corticosteroids that lack the free C21 hydroxyl group, such as FP and BDP, do not form free fatty acid esters [62]. The reversible esterification leads to the slow release of the active drug at the targeted site of action [63]. FLU contains a free hydroxyl group at $\mathrm{C} 21$ and can potentially undergo esterification, as it was demonstrated for ciclesonide and TAA [64]. FLU, TAA, and ciclesonide all contain a free hydroxyl group at $\mathrm{C} 21$ and can potentially undergo esterification. FLU, like BUD, is characterized by a brief pulmonary residence time, and it is assumed that inside the cell, it might be subjected to esterification due to the presence of a free C21 hydroxyl group. The intrapulmonary retention time of FLU is not known. In a study, we assessed the concentration of flunisolide in rat lungs after inhalation using gas chromatography [65]. Our study demonstrated a prolonged retention of inhaled FLU in rat lung tissue. In particular, retention in the lung would enhance the therapeutic index, either due to slow dissolution or the ability to form esters in the airways. The study demonstrated retention of FLU in rat lungs. This may be attributed to nonspecific binding processes, esterification, or gradient formation in the cell.

The absorption of drugs from the lungs to the systemic circulation is generally rapid, with high bioavailability for compounds with a wide range of physicochemical properties [66,67]. Different regions of the lungs are thought to have varying permeabilities to drugs according to their molecular properties, which dictate their interaction with the extracellular environment, including the lining fluid composition, cellular type and thickness, the extent and dimensions of intercellular junctions, blood flow, and competing clearance mechanisms. For example, the absorption of a small, hydrophilic molecule in human subjects was greatly enhanced by coapplying an absorption enhancer for a more peripheral delivery [68]. Although they may be delivered predominately to central or peripheral regions, current inhaled drugs do not exclusively target a particular region of the lungs, and clinical absorption profiles are composites of those of drug deposited and absorbed in different regions.

\section{Conclusion}

FLU, which was discovered in 1965 and used initially for nebulization, was approved in the United States in a CFC-pMDI for the treatment of asthma in 1981. Flunisolide was subsequently reformulated with a hydrofluoroalkane propellant. The reformulated flunisolide HFA with an integrated spacer is the most recent ICS product for asthma on the market in the United States and is the only product that combines an extrafine corticosteroid aerosol and a built-in spacer. The physical and chemical properties of FLU favor its prescription for nebulization. Clinical studies have demonstrated that nebulized FLU, at the commonly prescribed dosages, is efficient for asthma treatment in infants and that nonlocal or systemic side effects have been reported [69].

\section{Acknowledgements}

Not applicable

\section{Abbreviations}

ICS: inhaled corticosteroid;

BUD: budesonide;

FP fluticasone propionate;

FLU: flunisolide;

TAA: triamcinolone acetonide;

BDP: beclomethasone dipropionate;

PK: pharmacokinetic;

PD: pharmacodynamic;

DPI: dry-powder inhaler;

pMDI: $\quad$ pressurized metered dose inhalers;

MMAD: mass median aerodynamic diameter.

\section{References}

1. Derendorf H, Nave R, Drollmann A, Cerasoli F, Wurst W. Relevance of pharmacokinetics and pharmacodynamics of inhaled corticosteroids to asthma. Eur Respir J 2006;28:104250 .

2. Hubner M, Hochhaus G, Derendorf H. Comparative pharmacology, bioavailability, pharmacokinetics, and pharmacodynamics of inhaled glucocorticosteroids. Immunol Allergy Clin North Am 2005;25:469-88.

3. Dolovich MB, Ahrens RC, Hess DR, Anderson P, Dhand R, Rau JL, et al. Device selection and outcomes of aerosol therapy: evidence- based guidelines: American College of Chest Physicians/ American College of Asthma, Allergy, and Immunology. Chest 2005;127:335-71.

4. Vermeire P. European trends in inhalation therapy. Eur Respir Rev 1994;4:89-91.

5. Lavorini F, Corrigan CJ, Barnes PJ, Dekhuijzen PR, Levy ML, Pedersen S, et al. Retail sales of inhalation devices in European countries: so much for a global policy. Respir Med 2011;105:1099-103.

6. Melani AS. Nebulized corticosteroids in asthma and COPD. An Italian appraisal. Respir Care 2012;57:1161-74.

7. Daley-Yates PT. Inhaled corticosteroids: potency, dose equivalence and therapeutic index. Br J Clin Pharmacol 2015;80:37280 .

8. Derendorf H, Hochhaus G, Meibohm B, Mo"1lmann H, Barth J. Pharmacokinetics and pharmacodynamics of inhaled corticosteroids. J Allergy Clin Immunol 1998;101:S440-6.

9. Lipworth BJ. Clinical pharmacology of corticosteroids in bronchial asthma. Pharamcol Ther 1993;58:173-209.

10. Fabbri L, Burge PS, Croonenborgh L, Warlies F, Weeke B, Ciaccia A, et al. Comparison of fluticasone propionate with beclomethasone dipropionate in moderate to severe asthma treated for one year. Thorax 1993;48:817-23.

11. Ayres JG, Bateman ED, Lundback B, Harris TA. High dose fluticasone propionate, $1 \mathrm{mg}$ daily versus fluticasone propionate, $2 \mathrm{mg}$ daily, or budesonide, $1.6 \mathrm{mg}$ daily, in patients with chronic severe asthma. Eur Respir J 1995;8:579-86.

12. Agertoft L, Pedersen S. A randomised, double-blind dose reduction study to compare the minimal effective dose of budesonide Turbohaler and fluticasone propionate Diskhaler. J Allergy Clin Immunol 1997;99:773-80.

13. Yiallouros PK, Milner AD, Conway E, Honour JW. Adrenal 
function and high dose inhaled corticosteroids for asthma. Arch Dis Child 1997;76:405-10.

14. Lönnebo A, Grahnén A, Jansson B, Brundin RM, LingAndersson A, Eckernäs SA. An assessment of the systemic effects of single and repeated doses of inhaled fluticasone propionate and inhaled budesonide in healthy volunteers. Eur J Clin Pharmacol 1996;49:459-63.

15. Grahnén A, Eckernäs SA, Brundin RM, Ling-Andersson A. An assessment of the systemic activity of single doses of inhaled fluticasone propionate in healthy volunteers. $\mathrm{Br} \mathrm{J}$ Clin Pharmacol 1994;38:521-5.

16. Grahnén A, Jansson B, Brundin RM, Ling-Andersson A, Lönnebo A, Johansson M, et al. A dose-response study comparing suppression of plasma cortisol induced by fluticasone propionate from Diskhaler and budesonide from Turbohaler. Eur J Clin Pharmacol 1997;52:261-7.

17. Thorsson L, Dahlström K, Edsbäcker A, Källén A, Paulson J, Wirén JE. Pharmacokinetics and systemic effects of inhaled fluticasone propionate in healthy subjects. Br J Clin Pharmacol 1997;43:155-61.

18. Boorsma M, Andersson N, Larsson P, Ullman A. Assessment of the relative systemic potency of inhaled fluticasone and budesonide. Eur Respir J 1996;9:1427-32.

19. Clark DJ, Grove A, Cargill RI, Lipworth BJ. Comparative adrenal suppression with inhaled budesonide and fluticasone propionate in adult asthmatic patients. Thorax 1996;51:262-6.

20. Clark DJ, Lipworth BJ. Adrenal suppression with chronic dosing of fluticasone propionate compared with budesonide in adult asthmatic patients. Thorax 1997;52:55-8.

21. Derom E, Van Schoor J, Verhaeghe W, Vincken W, Pauwels R. Systemic effects of inhaled fluticasone propionate and budesonide in adult patients with asthma. Am J Respir Crit Care Med 1999;160:157-61.

22. Brutsche MH, Brutsche IC, Munavvar M, Langley SJ, Masterson CM, Daley-Yates PT, et al. Comparison of pharmacokinetics and systemic effects of inhaled fluticasone propionate in patients with asthma and healthy volunteers: a randomised crossover study. Lancet 2000;356:556-61.

23. Möllman H, Wagner M, Meibohm B, Hochhaus G, Barth J, Stöckmann R, et al. Pharmacokinetic and pharmacodynamic evaluation of fluticasone propionate after inhaled administration. Eur J Clin Pharmacol 1998;53:459-67.

24. Yanai M, Hatazawa J, Ojima F, Sasaki H, Itoh M, Ido T. Deposition and clearance of inhaled 18FDG powder in patients with chronic obstructive pulmonary disease. Eur Respir J 1998;11:1342-8.

25. Melchor R, Biddiscombe M, Mak V, Short M, Spiro S. Lung deposition patterns of directly labelled salbutamol in normal subjects and in patients with reversible airflow obstruction. Thorax 1993;48:506-11.

26. Niven RW. Atomization and nebulizers. In: Hickey AJ, editor. Inhalation aerosol: Physical and biological basis for therapy. New York: Marcel Dekker; 1996. p. 273-312.

27. O'Callaghan C, Barry PW. The science of nebulised drug delivery. Thorax 1997;52:531-44.

28. Dalby RN, Tiano SL, Hickey AJ. Medical devices for the delivery of therapeutic aerosols to the lungs. In: Hickey AJ, editor. Inhalation aerosol: Physical and biological basis for therapy. New York: Marcel Dekker; 1996. p 441-73.

29. Dhand R. Nebulizers that use a vibrating mesh or plate with multiple apertures to generate aerosol. Respir Care 2002;47:1406-146. discussion 1416-8.

30. Fink JB, Simmons R. Nebulization of steroid suspension: an in vitro evaluation of the Aeroneb®Go nebulizer and the Pari ${ }^{\circledR L C}+$ nebulizers. Chest 2004;126:816S-7.
31. Amani A, York P, Chrystyn H, Clark BJ. Evaluation of a nanoemulsion-based formulation for respiratory delivery of budesonide by nebulizers. AAPS Pharm Sci Tech 2010;11: 1147-51.

32. Lawrence MJ, Rees GD. Microemulsion-based media as novel drug delivery systems. Adv Drug Deliv Rev 2000;45:89-121.

33. Kamin W, Schwabe A, Krämer I. Inhalation solutions: which one are allowed to be mixed? Physico-chemical compatibility of drug solutions in nebulizers. J Cyst Fibros 2006;5:205-13.

34. Melani AS. Effects on aerosol performance of mixing of either budesonide or beclomethasone dipropionate with albuterol and ipratropium bromide. Respir Care 2011;56:319-26.

35. O'Callaghan CL, White JA, Jackson JM, Barry PW, Kantar A. Nebulisation of corticosteroid suspensions and solutions with a beta(2) agonist. J Pharm Pharmacol 2008;60:601-5.

36. Tashkin DP. A review of nebulized drug delivery in COPD. Int J Chron Obstruct Pulmon Dis 2016;11:2585-96.

37. Pleasants RA, Hess DR. Aerosol delivery devices for obstructive lung diseases. Respir Care 2018;63:708-33.

38. Melani AS, Sestini P, Aiolfi S, Barbato N, Canessa P, De Angelis G, et al. GENebu Project: home nebulizer use and maintenance in Italy. Eur Respir J 2001;18:758-63.

39. Wood JA, Wilson RS, Bray C. Changes in salbutamol concentration in the reservoir solution of a jet nebulizer. Br J Dis Chest 1986;80:164-9.

40. McCallion ON, Taylor KM, Thomas M, Taylor AJ. Nebulization of fluids of different physicochemical properties with air-jet and ultrasonic nebulizers. Pharm Res 1995;12: 1682-8

41. Högger P, Rohdewald P. Glucocorticoid receptors and fluticasone propionate. Rev. Contemp Pharmacother 1998;9:501-22.

42. O'Callaghan C, White J, Barry P, Kantar A. Analysis of the output of beclomethasone dipropionate from different nebulisers. Riv Ital Pediatr 2000;26:821-4.

43. O'Callaghan C, White J, Jackson J, Barry P, Kantar A. The output of flunisolide from different nebulisers. J Pharm Pharmacol 2002;54:565-9.

44. O'Callaghan C, White J, Jackson J, Barry PW, Kantar A. Delivery of nebulized budesonide is affected by nebulizer type and breathing pattern. J Pharm Pharmacol 2005;57:787-90.

45. O'Callaghan C, White JA, Kantar A. Nebulization of corticosteroids to asthmatic children: large variation in dose inhaled. Respirology 2014;19:276-9.

46. O'Callaghan C. Particle size of beclomethasone dipropionate produced by two nebulisers and two spacing devices. Thorax 1990;45:109-11.

47. Todd GR. Nebulised fluticasone. Thorax 2000;55:346-47.

48. Storr J, Lenney CA, Lenney W. Nebulised beclomethasone dipropionate in preschool asthma. Arch Dis Child 1986;61: 270-3.

49. Webb MS, Milner AD, Hiller EJ, Henry RL. Nebulised beclomethasone dipropionate suspension. Arch Dis Child 1986;61:1108-10.

50. Barry PW, O'Callaghan C. An in vitro analysis of the output of budesonide from different nebulizers. J Allergy Clin Immunol 1999; 104:1168-73.

51. Heyder J, Svartengren MU. Basic principles of particle behavior in human respiratory tract. In: Bisgaard $\mathrm{H}, \mathrm{O}^{\prime} \mathrm{Callaghan} \mathrm{C}$, Smaldone GC, Editors. Drug delivery to the lung. New York: Marcel Dekker; 2002. p. 21-45.

52. Bäckman P, Adelman H, Petersson G, Jones CB. Advances in inhaled technologies: understanding the therapeutic challenge, predicting clinical performance, and designing the optimal inhaled product. Clin Pharmacol Ther 2014;95:509-20.

53. Grainger CI, Saunders M, Buttini F, Telford R, Merolla LL, 
Martin GP, et al. Critical characteristics for corticosteroid solution metered dose inhaler bioequivalence. Mol Pharm 2012;9:563-9.

54. Riley T, Christopher D, Arp J, Casazza A, Colombani A, Cooper A, et al. Challenges with developing in vitro dissolution tests for orally inhaled products (OIP's). AAPS Pharm Sci Tech 2012;13:978-89.

55. Buttini F, Miozzi M, Balducci AC, Royall PG, Colombo P, Brambilla G, et al. Differences in physical chemistry and dissolution rate of solid particle aerosols from solution inhalers. Int J Pharm 2014;465:42-51.

56. Sakagami M, Li H, Venitz J. In vivo-relevant transwell dishbased dissolution testing for orally inhaled corticosteroid products. Pharm Res 2019;36:95.

57. Wiedmann TS, Bhatia R, Wattenberg LW. Drug solubilization in lung surfactant. J Control Release 2000;65:43-7.

58. Hallman M. Recycling of surfactant: A review of human amniotic fluid as a source of surfactant for treatment of respiratory distress syndrome. Rev Perinat Med 1989;6:197-226.

59. Derendorf H, Hochhaus G, Krishnaswami S, Mollmann H. Systemic disposition and effects of inhaled corticosteroids. In: Schleimer RP, O'Byrne PM, Szefler SJ, and Brattsand R, editors. Inhaled steroids in asthma. Optimizing effects in the airways. New York: Marcel Dekker; 2002. p. 247-72.

60. Derendorf H, Hochhaus G, Rohatagi S, Möllmann H, Barth J, Sourgens H, et al. Pharmacokinetics of triamcinolone acetonide after intravenous, oral, and inhaled administration. J Clin Phramacol 1995;35:302-5.

61. Miller-Larsson A, Mattsson H, Hjertberg E, Dahlbäck M, Tunek A, Brattsand R. Reversible fatty acid conjugation of budesonide: Novel mechanism for prolonged retention of topically applied steroid in airway tissue. Drug Metab Dispos 1998;26:623-30.

62. Hochberg RB. Biological esterification of Steroids. Endocr Rev 1998;19:331-48.

63. Miller-Larsson A, Janssen P, Runstròm A, Brattsand R. Prolonged airway activity and improved selectivity of budesonide possibly due to esterification. Am J Respir Crit Care Med 2000;162:1455-1461.

64. Kelly HW. Comparative potency and clinical efficacy of inhaled corticosteroids. Respir Care Clin N Am 1999;5:53753.

65. Kantar A, Carloni M, Kulkarni N, Fedeli D, Falcioni G. Retention of flunisolide in rat lungs after single inhalation. Europ J inflamm 2012;10:127-31.

66. Mathias NR, Timoszyk J, Stetsko PI, Megill JR, Smith RL. Wall epithelial cells: in vitro/in vivo correlation to predict lung absorption in rats. J Drug Target 2002;10:31-40.

67. Tronde A, Norden B, Marchner H, Wendel A-K, Lennernas H, Bengtsson UH. Pulmonary absorption rate and bioavailability of drugs in vivo in rats: structure-absorption relationships and physicochemical profiling of inhaled drugs. J Pharm Sci 2003;92:1216-33.

68. Bondesson E, Bengtsson T, Nilsson LE, Wollmer P. Effects of sodium taurocholate on the absorption of inhaled Tc-99mDTPA. Pharm Res 2006;23:2122-8.

69. Kantar A, Mroueh S, Fiocchi A. A reappraisal of the clinical efficacy of nebulized flunisolide in pediatric asthma: the Italian experience. Allergy Asthma Proc 2007;28:671-87. 